\title{
Bioanalysis
}

\section{The current skills gaps in analytical sciences are failing industry: debate at the 21st International Reid Bioanalytical Forum}

\section{1st International Reid Bioanalytical Forum, University of Surrey, Guildford, UK, 7-10 September 2015}

The 21st International Reid Bioanalytical Forum held between 7 and 10 September 2015, brought together over 100 scientists from around the world, representing industry, academia and vendors, for 4 days of engaging science at the University of Surrey in Guildford, UK. The scientific program consisted of 43 podium and 23 poster presentations from key opinion leaders and those just setting out on their scientific career. The latter being the focus of the meeting. One of the highlights of the forum was the debate. An expert panel helped spark off an active discussion among a passionate audience on the topic of 'The Current Skills Gaps in Analytical Sciences are Failing Industry.'

First draft submitted: 20 May 2016; Accepted for publication: 24 May 2016;

Published online: 17 June 2016

Keywords: bioanalytical $\bullet$ debate $\bullet$ reid $\bullet$ skills $\bullet$ training

\section{Historic}

The 21st International Reid Bioanalytical Forum brought together over 100 scientists from around the world, representing industry, academia and vendors for 4 days of engaging science at the University of Surrey in Guildford, UK. In keeping with the 40 years history of this popular meeting, a wide ranging, educational and thought provoking scientific program was balanced by a fun and active social program, where the highlights of the day were eagerly discussed by the delegates over excellent food and drink in memorable locations.

The scientific program consisted of 43 podium and 23 poster presentations from key opinion leaders and those just setting out on their scientific career. The content and the presenters reflected the 40 year heritage of the meeting and it's mantra to educate, exchange ideas and experiences (including where things go wrong) and to provide a safe platform for scientist who are at the early stage of their career and have limited experience of making scientific presentations. Scholarships to attend and present at the meeting were provided to four young scientists, who also made presentations. Topics for the presentations covered the analysis of small- and large-molecule drugs and biomarkers, development and implementation of new technologies, validation and regulatory aspects, and emerging trends in bioanalysis (e.g., microsampling).

\section{Debate}

One of the highlights of the forum was the debate. An expert panel consisting of Suzy Rigby, James Heaton and Allan Handley, helped spark off an active discussion among a passionate audience on the topic of 'The Current Skills Gaps in Analytical Sciences are Failing Industry'. The wide ranging and at times fervent discussion with diverse opinions covered topics such as:
Neil Spooner ${ }^{*, 1,2}$

\& Timothy Sangster ${ }^{3}$

'Spooner Bioanalytical Solutions Ltd., Hertford, UK

${ }^{2}$ School of Life \& Medical Sciences, University of Hertfordshire, UK ${ }^{3}$ Bioanalysis \& Immunology, Charles River Laboratories, Edinburgh, UK *Author for correspondence: neil@spoonerbioanalytical.co.uk 
- Whether there is indeed a skills gap;

- If there is one, is it a new phenomenon, or was it always such?

- Who might be responsible for any gap - academia, or industry?

It was generally agreed that there is a shortage of analytical scientists in Universities, particularly in the UK. Part of the reason for this was thought to be the high levels of tuition fees, which is driving students into other courses. In addition, some participants felt that the current career path for analytical scientists is not attractive, with poor job prospects and pay perceived to be the overriding issue. Some participants were also concerned that academic training of analytical scientists is not industrially focused enough.

A major talking point was around analytical chemistry being an enabling science and not in itself a specific focus within the academic space. This was highlighted by the recent growth in the availability of courses such forensic science, which have a large analytical chemistry and bioanalytical content, but that students identify with forensic science rather than analytical chemistry. It was suggested that this appears to be driven by popular media and specifically television shows. It was also put forward that this position also translates into postdoctoral research, where many people will be spending a large percentage of their time doing analytical or bioanalytical chemistry, but as part of their research into a specific problem and hence, analytical developments are made as an outcome of the questions raised along the research pathway, rather than being a focus in themselves.

The last part of the debate focused on what solutions might be available to the problem. These included the following diverse suggestions, mostly centered on the perceived situation in the UK:

- A media friendly 'Brian Cox' figurehead for bioanalysis [1];

- The establishment of a bioanalytical Masters program;

- The establishment of a qualification equivalent to the Royal Society of Chemistry's (RSC) Chartered Chemist [2], or the Association of Clinical Biochemists Chartered Scientist [3];

- Increasing awareness and visibility to younger scientists of the wide range of exciting roles that are available for bioanalytical scientists, particularly in smaller companies;
- Examine and learn from what other disciplines have successfully achieved (e.g., RSC, engineering)

At the end of the formal debate it was generally agreed that more needed to be done, but that progress would not be quick or easy, and that strong leadership would be required in order for anything to be achieved.

\section{Future}

The organizing committee of the International Reid Bioanalytical Forum is aiming to develop on these solutions, leading to a structured and positive course of action to contribute to closing the skills gap. As such, the International Reid Bioanaltyical Forum and South East Region Analytical Division of the RSC have come together to set up a 1-day interactive training course to give new career scientist an opportunity to develop their bioanalytical skills. The training will focus on troubleshooting bioanalytical issues and putting them into context of compound development. These are critical developmental skills for a new career bioanalytical scientist and normally only developed through having to live through the issues in real time. The course will be a combination of case studies drawn from the attendees own experiences, which they may or may not have found the solutions for, and also working through a full case study presented by industry experts. The day will also involve mentoring from experienced industrial representatives, to ensure the attendees get the most out of the opportunity. More details can be found online [4].

The International Reid Bioanalytical Forum has been a cornerstone in developing new career scientists and giving them the opportunity to present and discuss the key issues in bioanalysis over the years and this will be continuing at the next meeting in 2017. We look forward to welcoming you to the 22nd International Reid Bioanalytical Forum in 2017, where the focus will again be on a lively informal meeting where experienced and novice bioanalytical scientists can meet to contribute, discuss and learn from each other on this ever evolving and important subject matter. The 2017 Forum will be on the 4-7th September and for the first time in 42 years will not be in Guildford, but at a new venue - further details to follow. The Syndicate Committee (as the organizing committee is known) welcomes ideas and contributions from those that want to see progress in this important area of scientific endeavor, so please reach out to the committee with any suggestions or ideas.

\section{Disclaimer}

$\mathrm{N}$ Spooner and $\mathrm{T}$ Sangster were both involved in the organization of the 'Current Skills Gaps in Analytical Sciences are Failing Industry' debate, which was held at the 21st Interna- 
tional Reid Bioanalytical Forum. They were also involved in the organization of the Forum itself.

\section{Financial \& competing interests disclosure}

The authors have no relevant affiliations or financial involvement with any organization or entity with a financial inter-

\section{References}

1 Prof. Brian Cox, homepage. www.apolloschildren.com/index.php

2 Royal Society of Chemistry, Professional recognition for practising scientists.

www.rsc.org/careers/cpd/practising-scientists est in or financial conflict with the subject matter or materials discussed in the manuscript. This includes employment, consultancies, honoraria, stock ownership or options, expert testimony, grants or patents received or pending, or royalties.

No writing assistance was utilized in the production of this manuscript

3 The Association for Clinical Biochemistry and Laboratory Medicine. www.acb.org.uk

4 Events Organised by The Chromatographic Society. www.chromsoc.com/chromsocevents.aspx 